\title{
Monodisperse Lanthanide Oxysulfide Nanocrystals
}

\author{
Fei Zhao, Mei Yuan, Wen Zhang, and Song Gao* \\ Beijing National Laboratory for Molecular Sciences, \\ State Key Laboratory of Rare Earth Materials Chemistry and Applications, College of \\ Chemistry and Molecular Engineering, Peking University, Beijing 100871, China. \\ E-mail: gaosong@pku.edu.cn
}

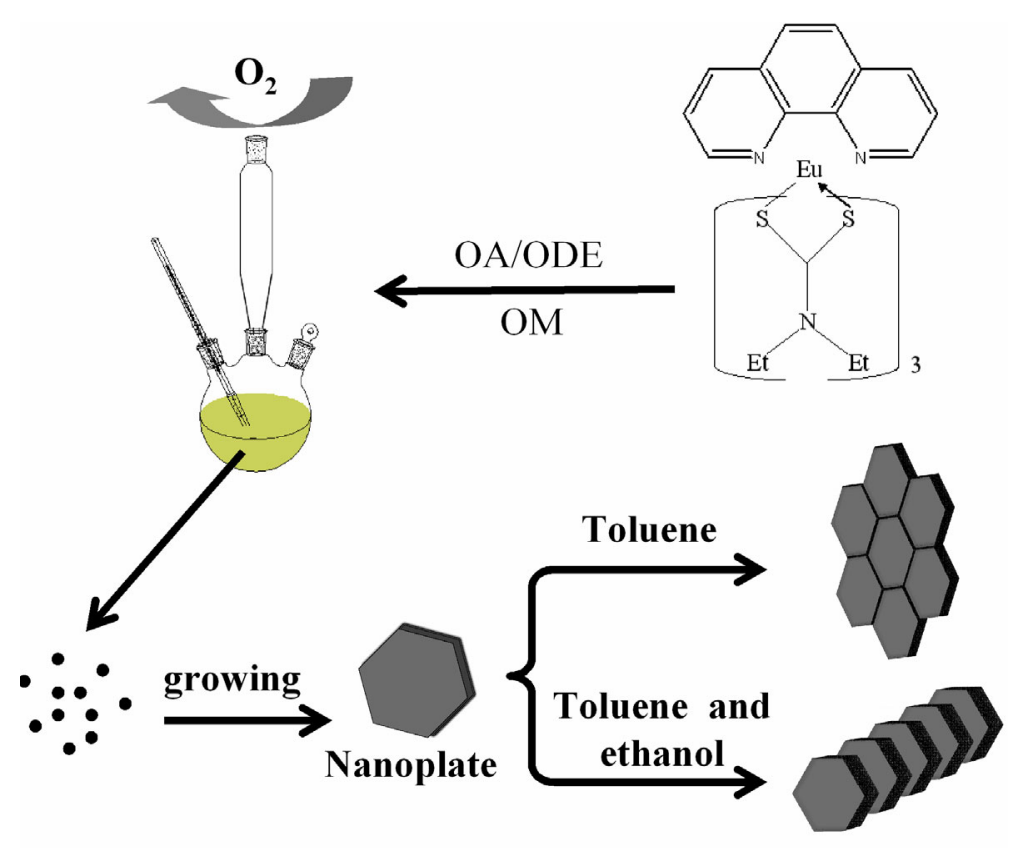

Scheme S1. Scheme of the process of the thermal decomposition and oxidation of $\left[\mathrm{Eu}(\mathrm{phen})(\mathrm{ddtc})_{3}\right]$ to $\mathrm{Eu}_{2} \mathrm{O}_{2} \mathrm{~S}$ nanoplates.

Detailed synthetic procedure of $\mathrm{Eu}_{2} \mathrm{O}_{2} \mathrm{~S}$ nanoplates and nanorods:

The lanthanide oxysulfide nanoplates were prepared by the thermal decomposition of molecular precursors $\left[\mathrm{Eu}(\right.$ phen $\left.)(\mathrm{ddtc})_{3}\right]$ (phen $=1,10$-phenanthroline; ddtc $=$ diethyl-dithiocarbamate). In a typical procedure, a slurry of $\left[\mathrm{Eu}(\mathrm{phen})(\mathrm{ddtc})_{3}\right](0.48 \mathrm{mmol}$, prepared by the literature method : Ivanov, R. A.; Korsakov, I. E.; Formanovskii, A. A.; Paramonov, S. E.; Kuz'mina, N. P.; Kaul, A. R. Russ. J. Coord. Chem. 2002, 28, 670.) was added to a mixed solvent composed of $6.4 \mathrm{~g}$ of oleylamine (OM, $24 \mathrm{mmol}$, Aldrich), $2.7 \mathrm{~g}$ of oleic acid (OA, $9.5 \mathrm{mmol}$, Aldrich) and $2.4 \mathrm{~g}$ of octadecene ODE, $9.5 \mathrm{mmol}$, Aldrich) at room temperature. The resulting solution was heated to 60 
${ }^{\circ} \mathrm{C}$ until a homogeneous and clear green-yellow solution was formed. Then the solution was rapidly heated to $290{ }^{\circ} \mathrm{C}$ in $5 \mathrm{~min}$ and was vigorously agitated for $45 \mathrm{~min}$. Some visible insoluble materials appear and the colloidal solution was cooled to $70{ }^{\circ} \mathrm{C}$. The products, $\mathrm{Eu}_{2} \mathrm{O}_{2} \mathrm{~S}$ nanoplates were precipitated by adding $30 \mathrm{~mL}$ of the mixture of hexane/acetone ( $\mathrm{v} / \mathrm{v}$ in 1:5) to the system. The suspension was centrifuged at $5000 \mathrm{rpm}$ for $7 \mathrm{~min}$ to afford a pale-yellow precipitate, which could dissolve in toluene $(15 \mathrm{~mL})$. Excess ethanol was added to reprecipitate the products, which was then separated and dried in a vacuum desiccator without a further size-selection process. If the $\mathrm{OM}$ was used as both the single reacting solvent and the stabilizer, we obtained $\mathrm{Eu}_{2} \mathrm{O}_{2} \mathrm{~S}$ short nanorods. All the products could be easily redispersed in nonpolar solvents such as hexane and toluene. The nanoplates could self-sssemble standing on the edge or lying flat on the TEM grid when we dispersed them in toluene/ethanol and toluene, respectively.

Characterization. The prepared nanocrystals were characterized by X-ray powder diffraction (XRD) with a Rigaku D/Max-2000 diffractometer equipped with a CuK radiation source $(\lambda=$ $0.15418 \mathrm{~nm}$ ). Transmission electron micrographs (TEM), high-resolution TEM (HRTEM) and energy-dispersed X-ray (EDX) characterization were performed with a Philips Tecnai F30 FEG-TEM operated at $300 \mathrm{kV}$. UV-visible absorption spectra were recorded using a Hitachi F-3010 spectrometer. Luminescence measurements were recorded on a F-4500 spectrophotometer. The Photoluminescent quantum yields (QYs) of $\mathrm{Eu}_{2} \mathrm{O}_{2} \mathrm{~S}$ and $\mathrm{Gd}_{2} \mathrm{O}_{2} \mathrm{~S}$ :Eu were determined by comparing the integral emission intensity of the dilutions of the concentrated nanocrystal solution in cyclohexane with that of rhodamine B in absolute ethanol at an excitation of 295-495 nm with collection between 500 and $750 \mathrm{~nm}$ at room temperature. the PL QYs of the as-prepared $\mathrm{Eu}_{2} \mathrm{O}_{2} \mathrm{~S}$ nanocrystals were determined to be $0.05 \%$ for short nanorods and to be $0.09 \%$ for nanoplates. The QY were determined to be $3.6 \%, 1.1 \%$ and $0.9 \%$ for $\mathrm{Gd}_{2} \mathrm{O}_{2} \mathrm{~S}: \mathrm{Eu}(1 \%), \mathrm{Gd}_{2} \mathrm{O}_{2} \mathrm{~S}: \mathrm{Eu}(5 \%)$, and $\mathrm{Gd}_{2} \mathrm{O}_{2} \mathrm{~S}: \mathrm{Eu}(15 \%)$, respectively. 


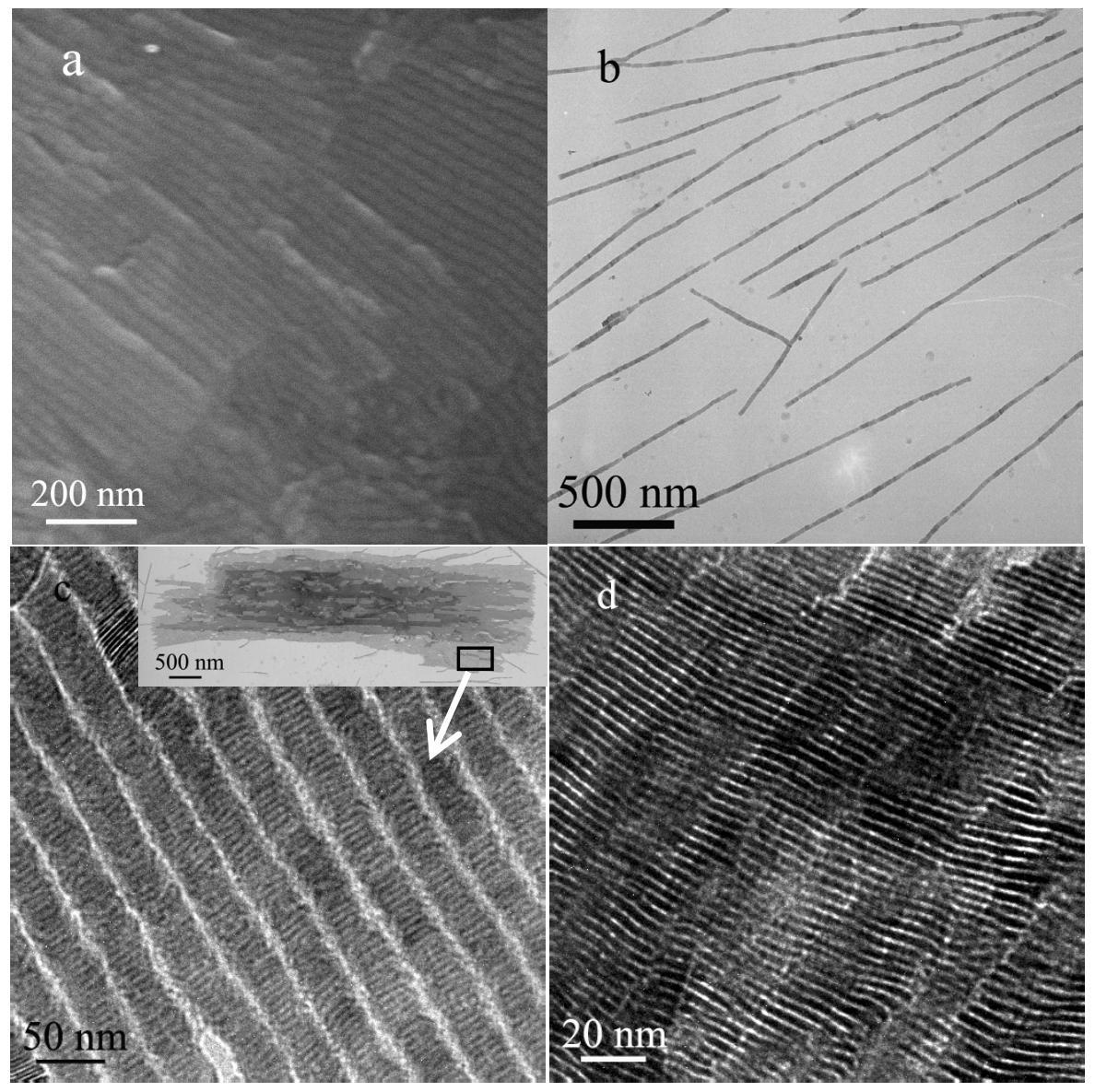

Figure S1. Microscopic images of of $\mathrm{Eu}_{2} \mathrm{O}_{2} \mathrm{~S}$ nanoplates $(15 \mathrm{~nm}$ in edge length, $1.5 \mathrm{~nm}$ in thickness) assembled to nanowires. (a) SEM images of the nanoplates. (SEM images were obtained with a DB-235 focused ion beam (FIB) system) (b) TEM images of the separated nanowires. (c) TEM images of the nanoplates ( insert is the TEM image viewed in a large scale), which indicated that the nanoplates inclined to other nanoplates. (d) TEM images of the nanoplates standing vertically on the TEM grids. 


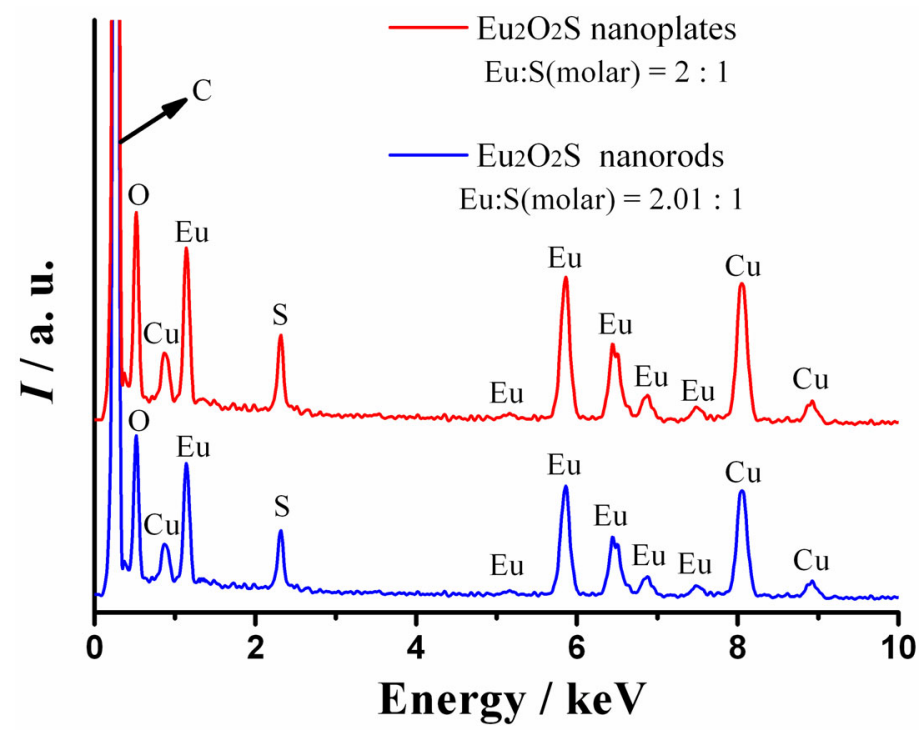

Figure S2. Energy-dispersive X-ray analysis (EDX) of $\mathrm{Eu}_{2} \mathrm{O}_{2} \mathrm{~S}$ nanoplates $(15 \mathrm{~nm}$ in edge length, $1.5 \mathrm{~nm}$ in thickness) and nanorods ( $6.5 \mathrm{~nm}$ in diameter, $10 \mathrm{~nm}$ in length), from which the atomic ratio of Eu:S were determined as 2:1 and 2.01:1, respectively.

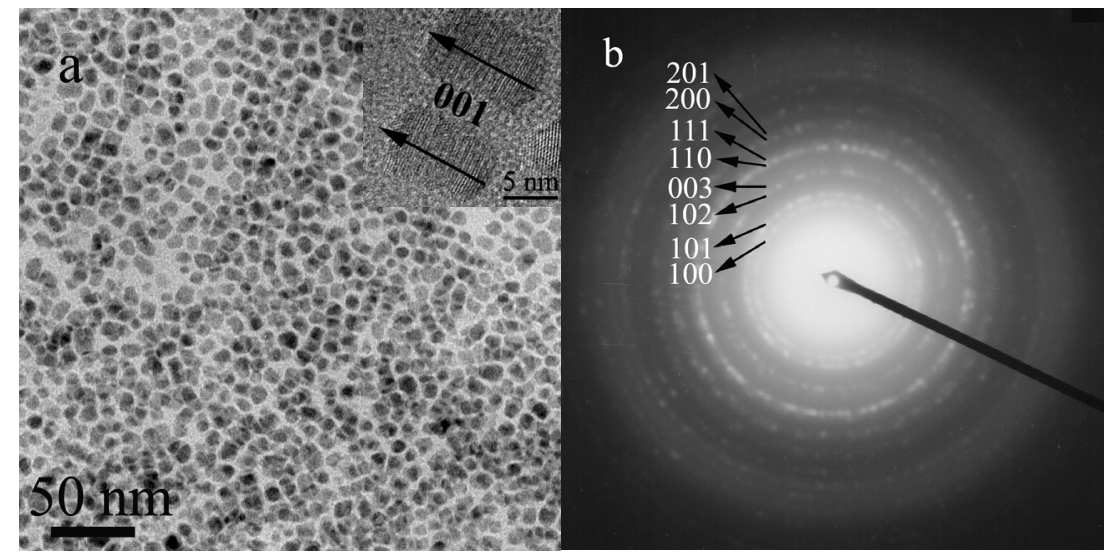

Figure S3. (a) TEM images of $\mathrm{Eu}_{2} \mathrm{O}_{2} \mathrm{~S}$ short nanorods (insert is the HRTEM of two nanorods). (b) ED pattern of short nanorods. 

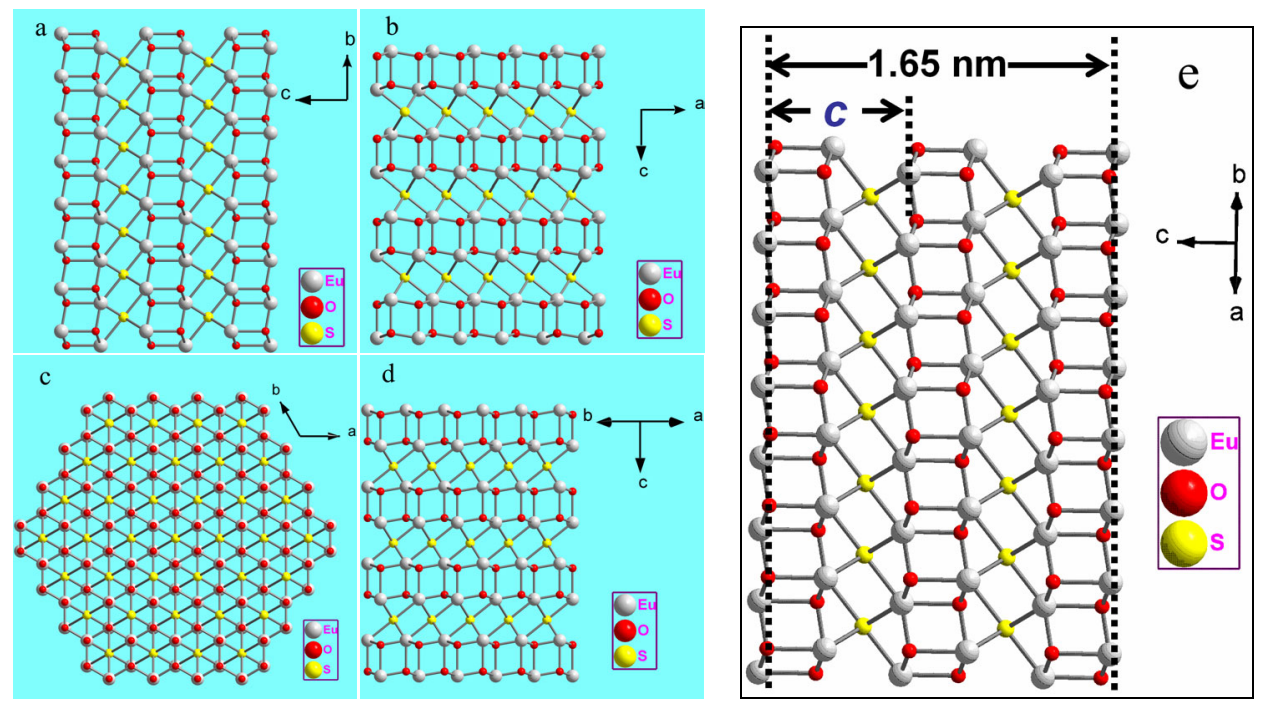

Figure S4. The crystal structure of the hexagonal $\mathrm{Eu}_{2} \mathrm{O}_{2} \mathrm{~S}$ viewed from different orientations. (a) from a axis; (b) from $b$ axis; (c) from $c$ axis. (d) from $a+b$ axis. The structure consists of $a$ three-dimensional framework where the $\mathrm{O}^{2-}$ and $\mathrm{S}^{2-}$ anions are separated in distinct sheets with the $\mathrm{Eu}^{3+}$ located in the interstitial sites in a seven-fold coordination, with a capped octahedron configuration in which the seventh atom, an oxygen, has been added to a triangular axis and subsequently the conventional P hexagonal cell (Llanos, J.; Sánchez, V.; Mujica, C.; Buljan, A. Mater. Res. Bull. 2002, 37, 2285.) (e) the nanoplates with thickness of 1.6-1.7 nm are regarded to be composed of c.a. 2.5 unit $(\sim 1.65 \mathrm{~nm})$ along the $c$ direction.

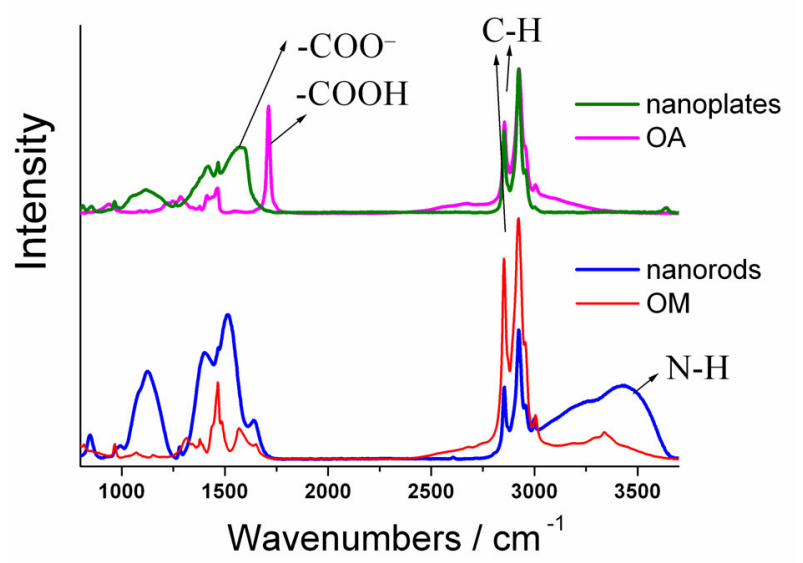

Figure S5 FT-IR spectra of $\mathrm{Eu}_{2} \mathrm{O}_{2} \mathrm{~S}$ nanorods, nanoplates and oleylamine (OM), oleic acid (OA) From the spectra, we observed the peaks of $-\mathrm{COO}\left(1550-1600 \mathrm{~cm}^{-1}\right)$ in nanoplates instead of the peak of $-\mathrm{COOH}$ in free $\mathrm{OA}\left(1712 \mathrm{~cm}^{-1}\right)$. The peaks of OM in nanorods are similar to that of free OM. OA have adsorbed to the nanocrystal surface more strongly than OM. (Ref. Willis, A. L.; Turro, N. J.; O'Brien, S. Chem. Mater. 2005, 17, 5970.) 


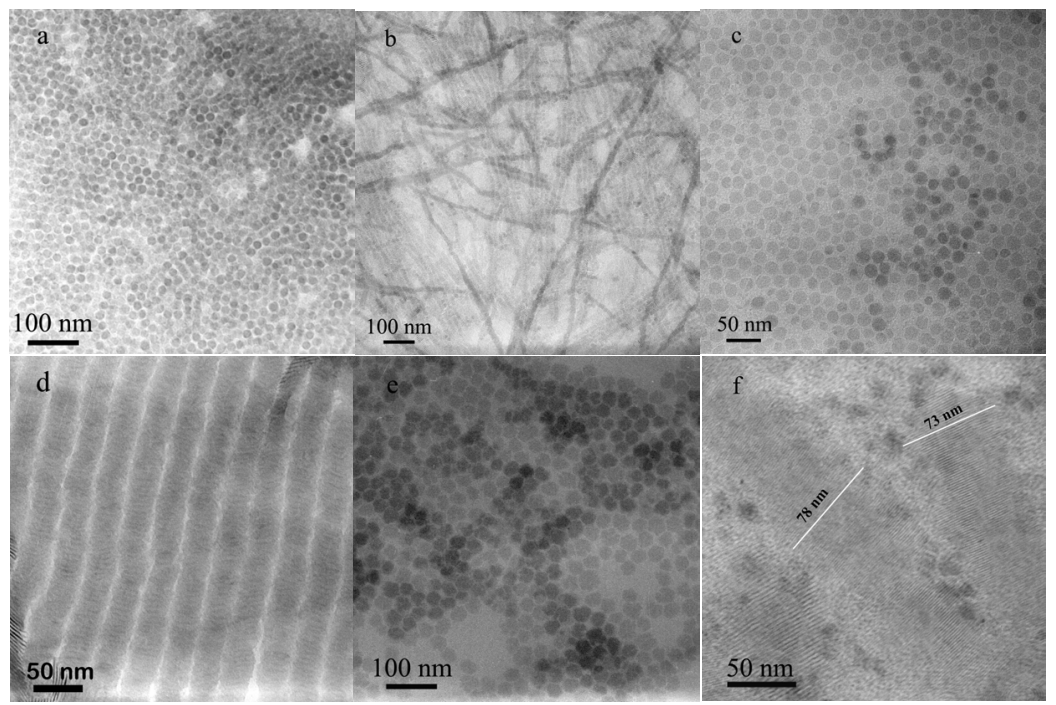

Figure S6. TEM images of $\mathrm{Eu}_{2} \mathrm{O}_{2} \mathrm{~S}$ nanoplates and nanodisks with different sizes. (a) and (b) The nanodisks with $15 \pm 0.5 \mathrm{~nm}$ in diameter and $1.6 \mathrm{~nm}$ in thickness self-assembled to nanowires $(0.36 \mathrm{~g}$ of $\left[\mathrm{Eu}(\mathrm{phen})(\mathrm{ddtc})_{3}\right], 1.3 \mathrm{~g}$ of OA, $10 \mathrm{~g}$ of OM, $\left.290^{\circ} \mathrm{C}, 50 \mathrm{~min}\right)$. (c) The nanodisks with $18 \pm 1 \mathrm{~nm}$ in diameter $\left(0.42 \mathrm{~g}\right.$ of $\left[\mathrm{Eu}(\right.$ phen $\left.)(\mathrm{ddtc})_{3}\right], 1.5 \mathrm{~g}$ of OA, $3.75 \mathrm{~g}$ of $\left.\mathrm{OM},, 270^{\circ} \mathrm{C}, 40 \mathrm{~min}\right)$. (d) and (e) The nanoshplats with $17 \pm 0.5 \mathrm{~nm}$ in diameter and $2.0 \mathrm{~nm}$ in thickness self-assembled to nanowires. (0.32 $\mathrm{g}$ of [Eu(phen)(ddtc) $\left.)_{3}\right], 2.3 \mathrm{~g}$ of OA, $5.5 \mathrm{~g}$ of OM , $2.1 \mathrm{~g}$ of ODE, $300^{\circ} \mathrm{C}, 55 \mathrm{~min}$ ). (f) The nanosheets with $75 \pm 5 \mathrm{~nm}$ in diameter and $1.6 \mathrm{~nm}$ in thickness $(0.42 \mathrm{~g}$ of [Eu(phen)(ddtc) 3 ], $1.5 \mathrm{~g}$ of $\mathrm{OA}, 3.75 \mathrm{~g}$ of $\left.\mathrm{OM}, 270^{\circ} \mathrm{C}, 40 \mathrm{~min}\right)$.

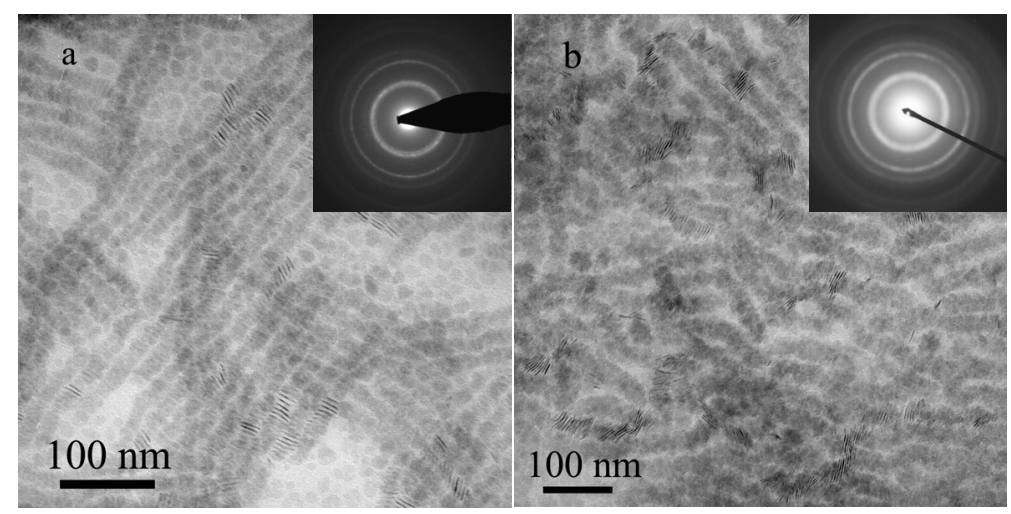

Figure S7. (a) TEM images of $\mathrm{Gd}_{2} \mathrm{O}_{2} \mathrm{~S}$ nanoplates with $21 \pm 0.5 \mathrm{~nm}$ in diameter and $2 \mathrm{~nm}$ in thickness self-assembled to nanowires ( [0.23 g of Gd(phen)(ddtc) 3 ], $1.65 \mathrm{~g}$ of OA, $4.0 \mathrm{~g}$ of OM, $1.5 \mathrm{~g}$ of $\mathrm{ODE}, 300^{\circ} \mathrm{C}, 35 \mathrm{~min}$ ) (insert, ED pattern). (b) TEM images of $\mathrm{Sm}_{2} \mathrm{O}_{2} \mathrm{~S}$ nanoplates with $25 \pm 1 \mathrm{~nm}$ in diameter and $2 \mathrm{~nm}$ in thickness ( [0.36 $\mathrm{g}$ of $\left.\mathrm{Gd}(\mathrm{phen})(\mathrm{ddtc})_{3}\right], 2.7 \mathrm{~g}$ of OA, $7.6 \mathrm{~g}$ of $\left.\mathrm{OM}, 325^{\circ} \mathrm{C}, 33 \mathrm{~min}\right)$ (insert, ED pattern). 


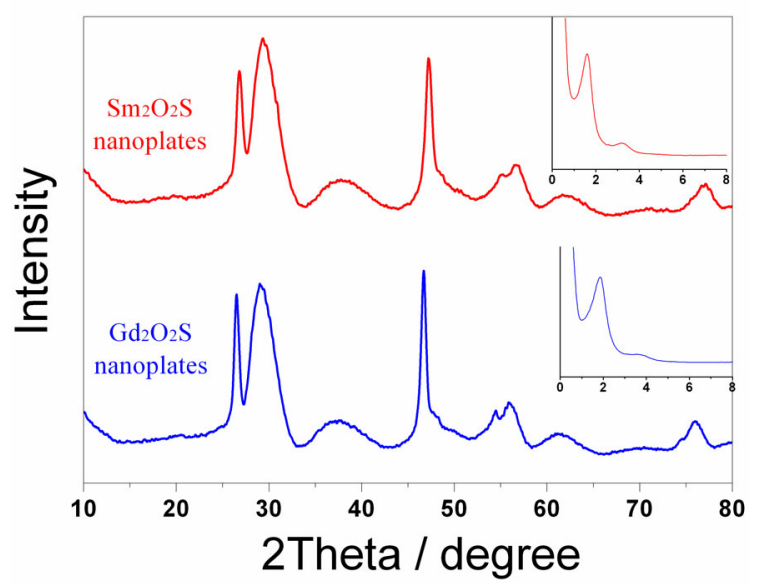

Figure S8. Powder XRD patterns of $\mathrm{Gd}_{2} \mathrm{O}_{2} \mathrm{~S}$ nanoplates and $\mathrm{Sm}_{2} \mathrm{O}_{2} \mathrm{~S}$ nanoplates (insert are the small-angle XRD patterns of the superlattice of nanowires).

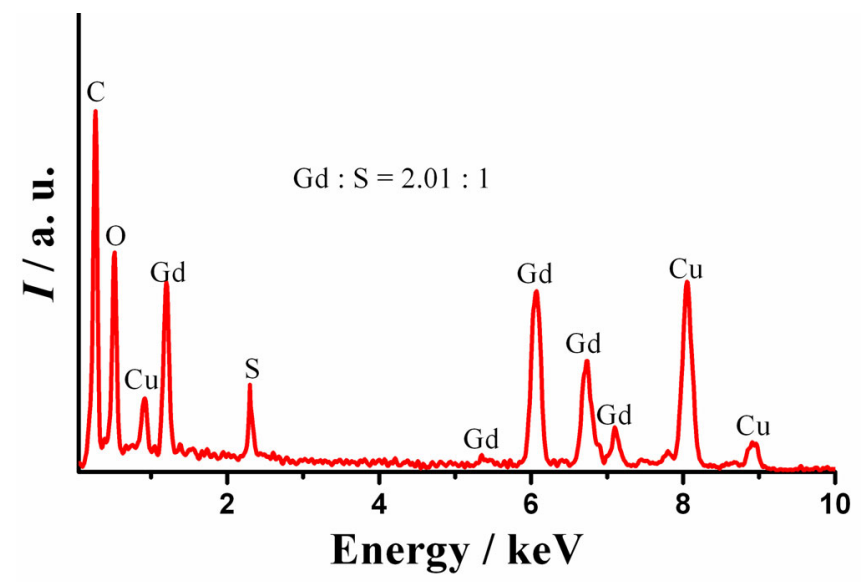

Figure S9. Energy-dispersive X-ray analysis (EDX) of $\mathrm{Gd}_{2} \mathrm{O}_{2} \mathrm{~S}$ nanoplates from which the atomic ratio of $\mathrm{Gd}: \mathrm{S}$ was determined as 2.01:1.

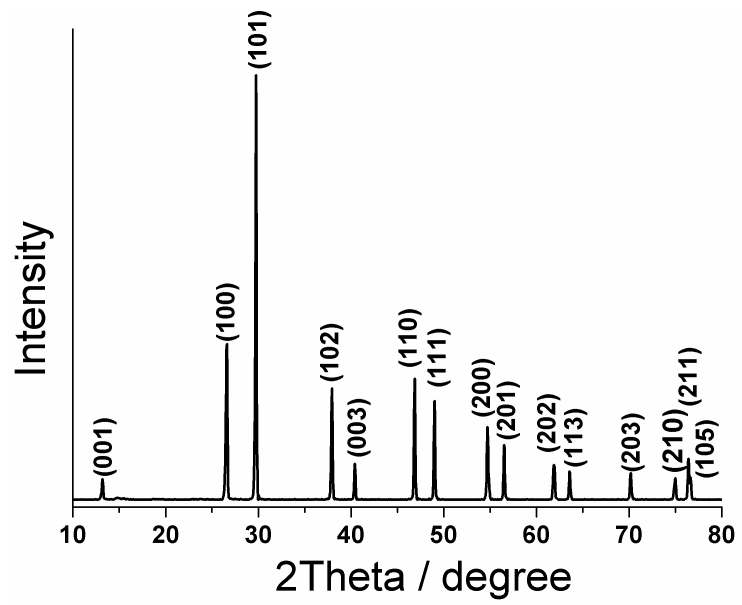

Figure S10. Powder XRD pattern of bulk $\mathrm{Eu}_{2} \mathrm{O}_{2} \mathrm{~S}$ crystals of hexagonal group of $\mathrm{P}-3 \mathrm{~m} 1$ (synthesized by using the method in literature: Reddy, K. R.; Annapurna, K.; Buddhudu, S. Mater. Res. Bull. 1996, 31, 1355. ). 


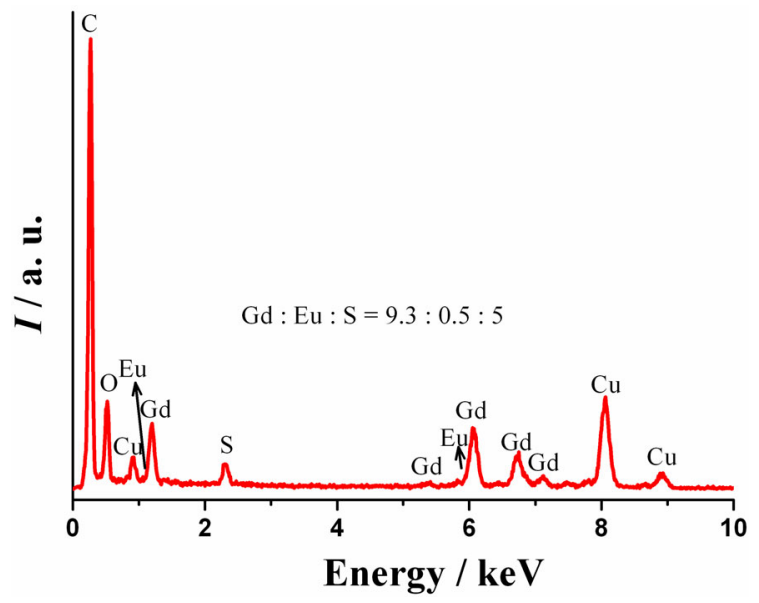

Figure S11. Energy-dispersive X-ray analysis (EDX) of $\mathrm{Gd}_{2} \mathrm{O}_{2} \mathrm{~S}$ : Eu (5\%) nanoplates from which the atomic ratio of $\mathrm{Gd}: \mathrm{Eu}: \mathrm{S}$ was determined as 9.3:0.5:5.
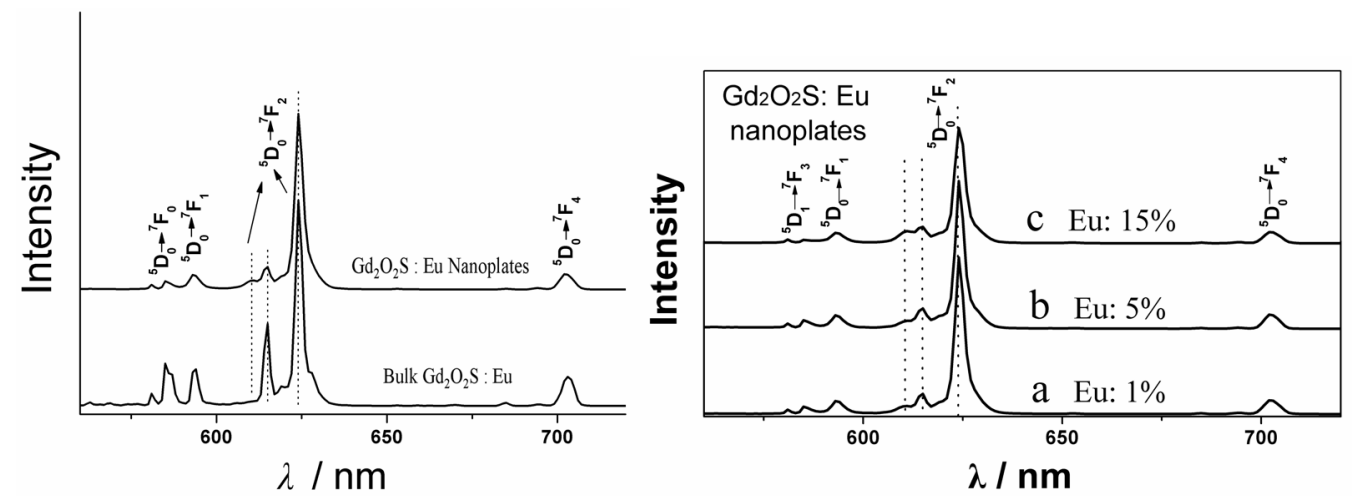

Figure S12. Room-temperature fluorescence emission spectra (Hitachi F-4500) of $\mathrm{Gd}_{2} \mathrm{O}_{2} \mathrm{~S}$ : Eu nanoplates (a) Eu: $1 \%, \lambda_{\mathrm{ex}}=237 \mathrm{~nm}$; (b) Eu: $5 \%, \lambda_{\mathrm{ex}}=229 \mathrm{~nm}$; (c) Eu: $15 \%, \lambda_{\mathrm{ex}}=228 \mathrm{~nm}$. 